\title{
The Effect of Manure Application on The Floristic Composition on a Permanent Grassland in Petrova, Maramureş
}

\author{
Adela L. BOTIŞ*, Gheorghe MIHAI, Nicuşor SIMA, Doru CRISTE, Iulia MEDREA, Bogdan FĂGĂDAR \\ Faculty of Animal Science and Biotechnologies, University of Agricultural Sciences and Veterinary \\ Medicine, 3-5 Mănăştur Street, 400372 Cluj-Napoca, Romania \\ *Corresponding author, email:
}

Bulletin UASVM Animal Science and Biotechnologies 71(2) / 2014,

Print ISSN 1843-5262; Electronic ISSN 1843-536X

DOI:10.15835/buasvmcn-asb:10472

\begin{abstract}
Organic agriculture has gained great popularity in the past years in Europe and it can solve problems regarding environmental pollution. Turning to organic farming does not mean ending progress in agriculture, but developing research into increasing production and quality of fodder so that the lack of food products would not become a problem in the future. The application of manure as fertilizer influences the floristic composition of grasslands, having a positive effect on the quality of forage by increasing the percentage of valuable species in the field and further on the health of the animals.
\end{abstract}

Keywords: fertilizers, flora, grassland, manure, organic

Introduction. A permanent grassland is formed from associations of species which has a variable repartition in space (Samfira et al., 2011) and the purpose of analyzing vegetation is to establish the first image on the capacity of production of the grassland and the quality of the herbs in it (Samfira and Moisuc, 2007). Despite low production costs, livestock grazing is declining in Europe, in part due to the difficulty managing herbage quantity and quality over weekly and annual time scales (Duru, 2011). Due to the large number of species in species-rich grasslands, fodder production is poorly estimated by eco-physiology or phyto-sociology alone. Due to their complexity, advisors discourage use of such grasslands even though they can provide environmental benefits (Bignal and McCracken, 2000).

Aims and objectives The aim of the research is to compare the effect of manure application on the flora composition on permanent grassland in Petrova, Maramureş. Since manure has an impact on the floristic composition of the pasture, it is expected that the effect of fertilization should increase the percentage of valuable species, especially legumes so that the grass and fodder obtained from it could be of a higher quality.

Materials and methods During the last three centuries there were many studies conducted in the area, most of them describing the vegetation here. These studies were carried out by a number of famous botanists. The experiment in Petrova, Maramureş, fertilized with manure and liquid organic fertilizer, is used in solving the question of the floristic changes after applying organic fertilizers on permanent grassland. The experiment is established on permanent grassland in the climate conditions of Petrova since October 2012. It is placed by randomized block method in 3 blocks with 13 experimental variants, each variant (except the witness) being fertilized with manure, solid, liquid and a mixture of the two, coming from the farms livestock. Each variant has a surface of $25 \mathrm{~m}^{2}$ half of it being harrowed. The variants were fertilized as follows: V1 is the witness, from V2 to V4 were fertilized with 50 to $100 \mathrm{t} /$ ha manure, from V5 to V7 was used 50-100t/ ha liquid manure, for V8 to V10 vas used a mixture 
of solid and liquid manure and for the last three was used 50-100t/ha fresh manure. To establish the floristic composition of each variant was used the metric frame method to determine how the fertilizers influenced the vegetation

Results and discussion. The application of manure on the field was done in the autumn of 2012 and also in 2013, results being obtained in the summer of 2013, two cuts and another two in 2014, the experiment being ongoing. The grassland on which the fertilizers were applied is a Festuca rubra L. - Agrostis capillaries L. meadow and the determination of the floristic composition was done before every cut. In this way, it could be seen how the manure affected the vegetation and especially the effect of it on the percentages of legumes and graminaceae plants on each variant treated with different quantities of manure or mix of manure. The effect of manure application on the permanent grassland was also influenced by the harrowing of the pasture, results on vegetation being different than on the variants, which were not harrowed.

On the harrowed variants, the percentage of graminaceae plants decreased, except on the ones which were fertilized with a medium quantity of liquid manure in which case the percentage of them increased from one year to another. In the case of the un-harrowed variants, the effect of fertilizers was the same as for the others, except for the variants fertilized with 100t/ha of liquid manure. As in the first case, the percentage of graminaceae plants increased.

For the legumes, organic fertilizers have a very good influence since the percentage of them in the field increased in every case, both on the harrowed variants and the un-harrowed. The best percentage of legumes was obtained, in the harrowed case, on the variant fertilized with 50t/ ha fresh manure. As for the un-harrowed field, the result is the same, the greatest percentage of legumes was obtained on the variants fertilized with the same type of manure and quantity. Similar results were noted by Bogdan (2012) who underlined that the percentage of legumes increases on grassland treated with manure, but the number of species decreases with almost 14\%.

Conclusion. Turning to ecological agriculture could be the best way to preserve the health of nature and could also be the start point of developing "environment friendly" techniques in controlling the quality of fodder.

Manure application on permanent grassland has a great effect on the floristic composition and on the quality of the vegetation obtained from such a pasture, especially when it is maintained in good conditions and accurate fertilized. As the results of the experiment in Petrova show, manure changes the composition of vegetation and has a benefic effect on the valuable species of plants. Increasing this percentage it is also increasing the quality of forage so that this characteristic for fodder would not be less appreciated in comparison with production.

\section{REFERENCES}

1. Bignal EM, DI McCracken (2000). The nature conservatin value of European traditional farming systems, Environ, Rev.8, 149-171.

2. Bogdan Anca (2012).Cercetări privind folosirea şi menţinerea pajiştilor montane cu low-put, PhD Thesis at The University of Agricultural Science and Veterinary Medicine, Cluj-Napoca.

3. Duru M (2012). Combining agroecology and management science to design field tools under high agrosystem structural or process uncertainty: Lessons from two case studies of grassland management 2011, Elsevier Ltd., DOI: 10.1016/j.agsy.2012. 09.002.

4. Samfira I, T Marușca, A Moisuc, Monica Hărmănescu, M Herbei, Veronica Sărățeanu, C Popescu (2011). Elemente metodologice aplicate în cercetarea pajiştilor, Timişoara.

5. Samfira I, Al Moisuc (2007). Ecopratotehnică, Ed. Eurobit, Timişoara. 